\title{
Experimental Investigation of Retrofitting Techniques for Steel Bridge Girders Subject to Fatigue Failure
}

\section{Mirza O*, Milner L and Mashiri F}

School of Computing, Engineering and Mathematics, Western Sydney University, Locked Bag 1797, Penrith South DC, NSW 1797, Australia

\begin{abstract}
Fatigue failure is major concern for infrastructure due to the increasing number of steel structures reaching the end of their design life each year. Increased loadings, deterioration due to weathering, climate change and human error also negatively impact the design life. Rehabilitating steel bridge girders rather than replacing the existing structure can provide an option for an economical and sustainable future. This paper presents the results of an experimental study which implements a simple retrofitting technique to combat fatigue failure. The retrofitting technique is applied to girders which have incurred fatigue cracking within the bottom flange. Experimental tests are performed on a riveted tapered 120-year-old girder and a new prefabricated hot rolled girder. The results from the experimental tests showed that fatigue cracking within the bottom flange of girders can be easily rehabilitated to increase the girder's capacity to that of their original design. By utilising this simple designed retrofitting technique, existing structures do not need to be replaced. The technique shown herein is a viable method for increasing the service life of steel girders providing for a sustainable future.
\end{abstract}

Keywords: Girder; Hydraulic press; Retrofit; Fastener; Stiffness; Slippage

\section{Introduction}

Fatigue is a mode of failure that affects $80-90 \%$ of all steel structures [1]. With more steel bridges reaching the end of their design life each year, fatigue failure is prominent and many steel bridges must undergo repair if they're to remain in service. The state of New South Wales in Australia has nearly 5000 steel bridges with $17 \%$ being older than 50 years old Henderson [2]. Although the risk of fatigue failure generally increases proportionally to the number of years steel bridges are in service, this is not always the case. Many studies have been conducted showing that poor detailing, increased loadings, imperfections, weld defects and holes can significantly reduce the fatigue life of the structure. This means that any structure is susceptible to fatigue whether the materials are old or new. Over the last century an increase in loading especially in the road and railway transportation industry has caused a significant impact to the design life of steel bridges. The increased loads experienced now were not accounted for in initial designs.

There are three phases that take place to produce fatigue failure: crack initiation, crack propagation and fracture. Crack initiation occurs from cyclic loading to which the material goes from its initial condition to the development of a macro-crack [3]. The crack propagation phase is the stable growth of the crack from the crack initiation phase [3]. The final phase is fracture where the unstable crack growth ultimately leads to the failure of the material. Fatigue can be further categorised into low cycle fatigue or high cycle fatigue dependant on the magnitude of stress and the number of cycles until failure [4]. When a structural component survives a large number of cycles between $10^{4}$ and $10^{8}$, high cycle fatigue is used to describe the situation [5]. Low cycle fatigue typically causes failure in the structural component in less than $10^{4}$ cycles [6]. The primary difference between high and low cycle fatigue is the stress regime in which they are loaded. The stress regime associated with high cycle fatigue typically operates within the linear elastic region of the stress-strain curve $[5,7,8]$. In contrast the stress regime associated with low cycle fatigue may enter the inelastic region of the stress-strain curve occasionally [5].

There are many ways to solve the issues resulting from fatigue such as replacing the structure; however, another solution is to retrofit.
Retrofitting is a viable solution for fatigue failure, as replacing entire structures consumes a lot time and money [9]. Although the retrofit should be simple and cost effective, it must also fix the problem adequately so there is no reoccurrence of fatigue. This study will focus on the fatigue strength of two girders, one being an old steel riveted girder and a new equivalent hot-rolled girder. The study will also design and implement a simple cost-effective retrofit that can be installed on steel bridges subjected to the same fatigue failure conditions. The retrofit will be designed so it can be installed in situ minimising the disruption of the bridge and reducing delays whilst it is being installed.

\section{Experimental Studies}

\section{Test specimens}

There are two test specimens; the 120-year-old girder and the 610 UB113 new equivalent girder. The test specimens are the same length being $6477 \mathrm{~mm}$ and have vertical stiffeners in the same locations. Figures $1 \mathrm{~A}$ and $1 \mathrm{~B}$ show the cross-sectional dimensions of the two girders.

The new hot-rolled girder varies from the RMS 120-year-old girder as it has a uniform cross section as shown in Figure 2, whereas the 120 -year-old girder is a tapered I beam which can be seen in Figure 3. The hot-rolled girder was selected due to its cross-sectional dimensions and moment capacity being relatively similar to the 120 -year old girder.

The 120-year-old girder is a riveted I section that has many defects

*Corresponding author: Olivia Mirza, Senior Lecturer and Academic Course Advisor for Fire Safety Engineering, School of Computing, Engineering and Mathematics, Western Sydney University, Locked Bag 1797, Penrith South DC NSW 1797, Australia, Tel: 4736 0402; E-mail: o.mirza@westernsydney.edu.au

Received December 11, 2017; Accepted January 02, 2018; Published January 03, 2018

Citation: Mirza O, Milner L, Mashiri F (2018) Experimental Investigation of Retrofitting Techniques for Steel Bridge Girders Subject to Fatigue Failure. J Steel Struct Constr 4: 138 doi: 10.4172/2472-0437.1000138

Copyright: ( 2018 Mirza O, et al. This is an open-access article distributed under the terms of the Creative Commons Attribution License, which permits unrestricted use, distribution, and reproduction in any medium, provided the original author and source are credited. 


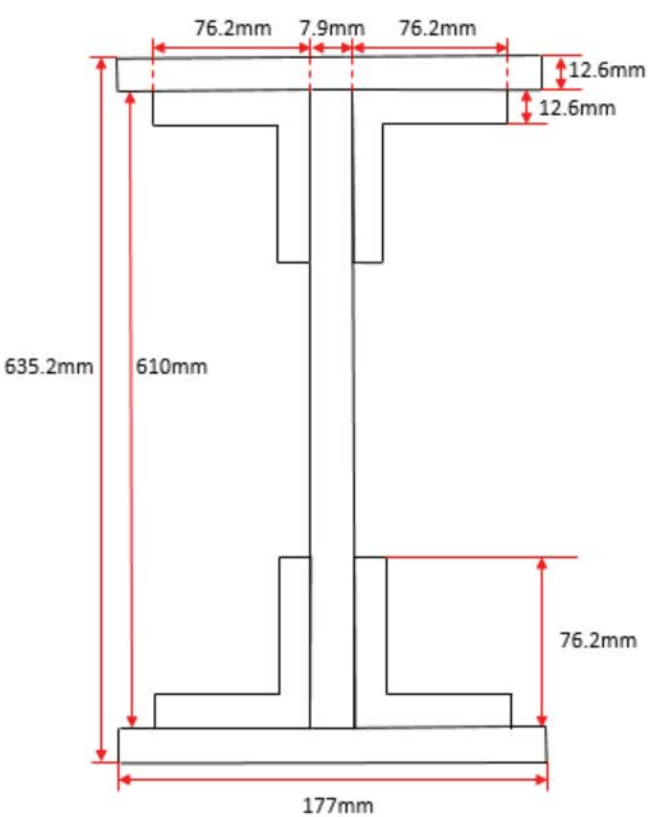

(A)

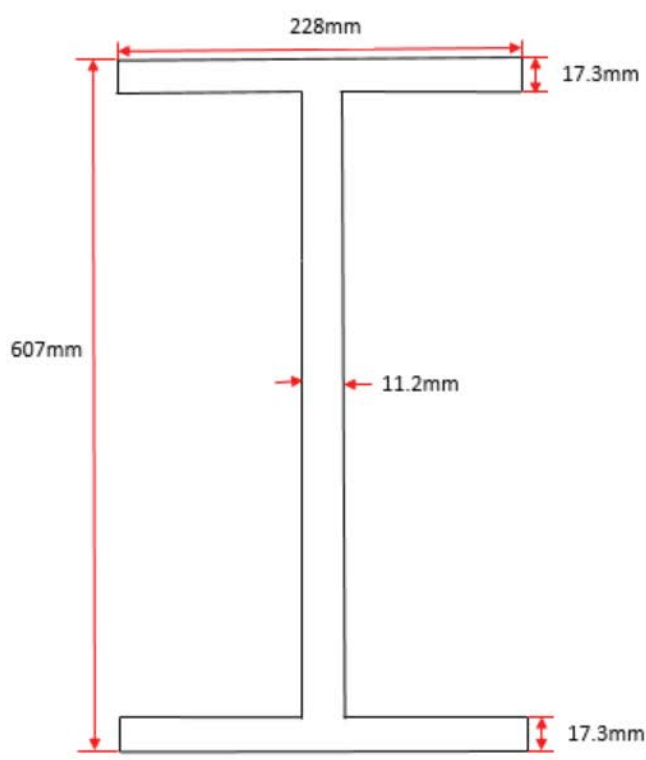

(B)

Figure 1: (A) Cross sectional dimensions at mid span of RMS 120-year-old girder, (B) Cross sectional dimension of EJF new equivalent girder.

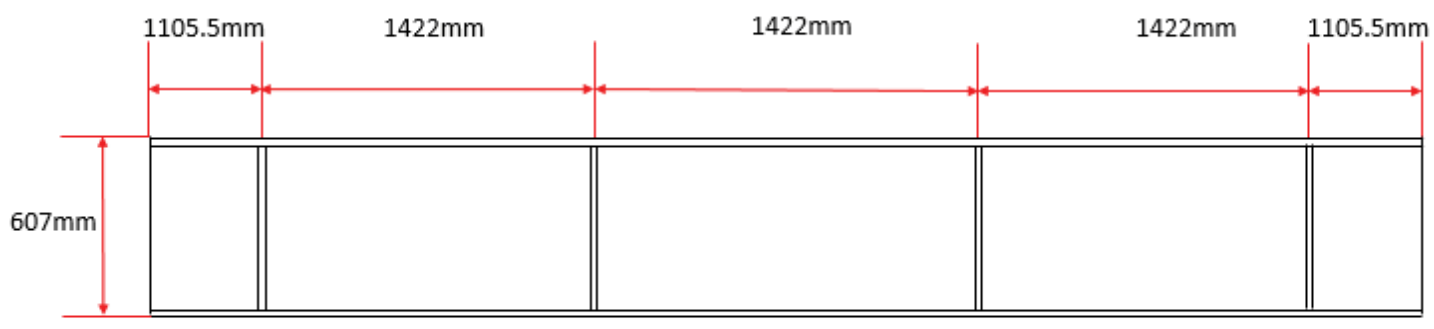

Figure 2: New equivalent girder.

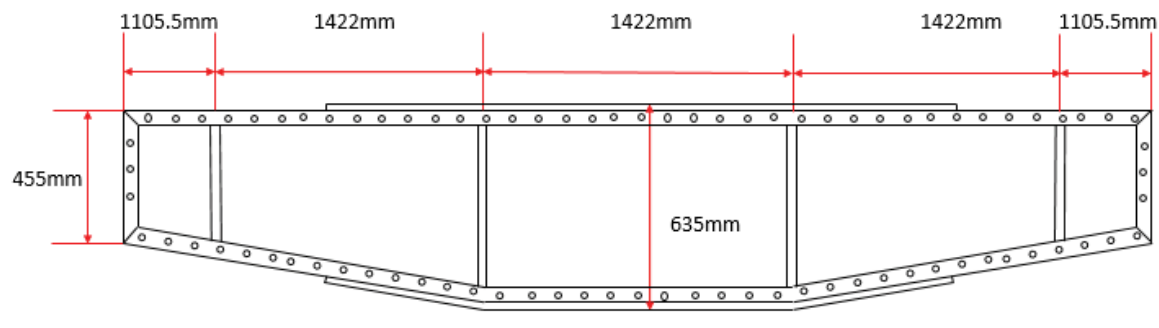

Figure 3: RMS 120-year-old girder.

present. One defect experienced by the 120 -year-old girder is corrosion, as the entire beam is covered in surface rust with some locations experiencing the corrosion more aggressively as the girder has started to pit. Another notable defect for the 120 -year-old girder is that it had rivets missing in some locations. The defects for the 120 -year-old girder are shown in Figure 4. The new hot-rolled 610UB113 girder has $7.9 \mathrm{~mm}$ vertical stiffeners fillet welded in place by EJF engineering to the flange and web. As expected the new equivalent has no defects present.

\section{Experimental setup}

The experimental testing was conducted within the Centre for Infrastructure Engineering testing laboratory which is located at Western Sydney University, Kingswood campus. The testing involved the use of the following equipment:

- $\quad$ Linear variable displacement transducers (LVDT)

- $1000 \mathrm{kN}$ hydraulic press 


\section{- Roller support system}

The experimental setup can be seen in Figure 5. LVDTs were placed at a distance of $1619.25 \mathrm{~mm}$ from either end to ensure the girders were deflecting symmetrically and at mid span at a distance of 3238.5 $\mathrm{mm}$ from either end to measure the overall deflection. The $1000 \mathrm{kN}$ hydraulic press applied the point load at mid-span. Roller supports were used $100 \mathrm{~mm}$ from the end of the girder to ensure the girders did not fall off the supports during testing.

\section{Test procedure}

Two types of test were conducted on each of the girders. A static fatigue test which was conducted upon the girders in their original state, that is, without the induced cracks or the subsequent retrofitting. The static fatigue tests were designed to determine the initial stiffness of the original girders by applying loads within their elastic response region. A static strength test until failure was also then conducted upon the retrofitted girders.

Static fatigue test: The static fatigue test consisted of applying a point load at the mid span of the girders using the $1000 \mathrm{kN}$ hydraulic press. The point load applied is to be within the elastic region of the stress vs. strain curve, which is where the beam will return to its undeformed state once the applied load is removed. This, correlates to not exceeding $60 \%$ of the ultimate applied point load capacity of the girder. The moment capacity of the girders has been calculated previously by Schroot [10]. Therefore, the ultimate applied load at mid span for a simply supported beam can be calculated with equation 1 .

$$
P_{\max }=\frac{4 * M_{\max }}{L}
$$

The length of the girder, $L$ is equal to $6.477 \mathrm{~m}$ for both girders. The ultimate section moment capacity, $M_{\max }$ of the 120 -year-old girder and the new equivalent girder is $874.5 \mathrm{kNm}$ and $921.2 \mathrm{kNm}$, respectively. Therefore, the ultimate applied point load at mid span for the 120-yearold girder is:

$$
P_{\max }=\frac{4 * M_{\max }}{L}=\frac{4 * 874.5}{6.477}=540.1 \mathrm{kN} \text {. }
$$

Therefore, the ultimate applied point load at mid span for the new equivalent girder is:

$$
P_{\max }=\frac{4 * M_{\max }}{L}=\frac{4 * 921.2}{6.477}=568.9 \mathrm{kN} .
$$

For the static fatigue tests in this investigation, the point load applied at mid span was reduced to $40 \%$ of the ultimate applied load capacity of the girder so the girders are well within the elastic region and will return to their undeformed state. For the 120-year-old girder this correlates to applying a $216 \mathrm{kN}$ point load at mid span. For the new equivalent girder, this correlates to $227.6 \mathrm{kN}$. The beams were loaded and then unloaded three times to ensure the results are accurate as the first loading is expected to cause the girders to settle on the supports. Table 1 summarises the loading schedule for the static fatigue test.

Static strength test until failure: The static strength test until failure consisted of applying a point load to the mid span of the artificially induced fatigue cracked retrofitted girders using the 1000 $\mathrm{kN}$ hydraulic press until failure occurred. This enabled a comparison of the behaviour of the old and new girder before and after the installation of the retrofit. The loads at $40 \%, 60 \%$ and $80 \%$ of the ultimate load of the girders were applied 3 times to remove errors from the results and ensure the test setup system was stable. The first loading was $40 \%$ of the ultimate applied point load capacity of the girders. The $40 \%$ loading is to be the same loading applied within the static fatigue test for the girders described above. Loadings of $60 \%$ and $80 \%$ were then applied to the girders. Finally, the beams were loaded until failure. Table 2 summarises the loading schedule for the static strength test until failure.

\section{Artificially induced fatigue crack}

A cyclic loading fatigue test could not be conducted for the experimental study as the testing equipment was not available. Hence a fatigue crack had to be artificially made to test the retrofitting technique and the ultimate performance of the retrofitted 120-year-old girder and the retrofitted new equivalent girder. The artificial fatigue crack was

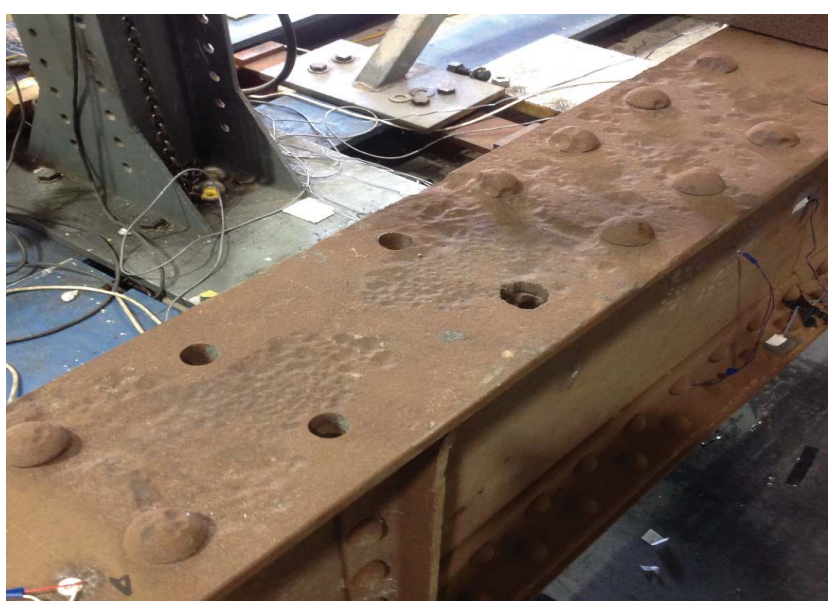

Figure 4: Defects for 120-year-old girder.

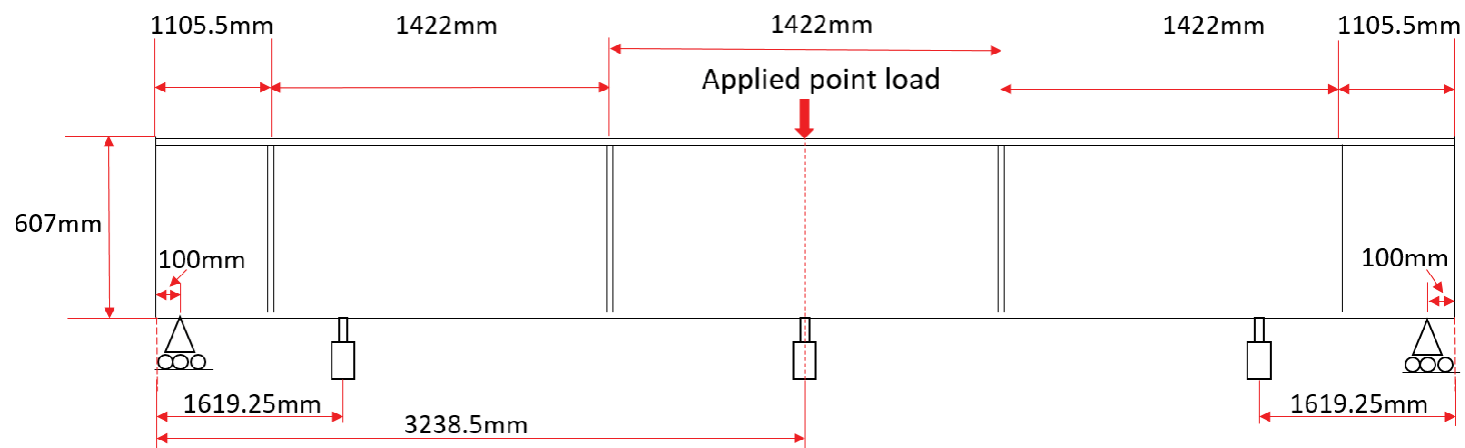

Figure 5: Experimental setup for girders 
Citation: Mirza O, Milner L, Mashiri F (2018) Experimental Investigation of Retrofitting Techniques for Steel Bridge Girders Subject to Fatigue Failure. J Steel Struct Constr 4: 138. doi: 10.4172/2472-0437.1000138

made within the bottom flange at mid span as that is to be the location with the expected maximum tensile stress, according to Schroot [10]. The artificial fatigue crack was created by cutting the bottom flange at mid span with an industrial bandsaw which is seen in Figure 6.

\section{Girder retrofitting technique}

The retrofitting technique for the girders is a way to combat fatigue that occurs at mid span within the bottom flange. The retrofit was required to be practical as it must be designed so it can be performed within a real-life situation to minimise disruption to bridge services. The retrofit performed was to combat an artificial fatigue crack at mid span within the two girders. The plate to be attached to the girders is $20 \mathrm{~mm}$ thick, $1410 \mathrm{~mm}$ in length and the width of the girder's flange which is $228 \mathrm{~mm}$ for the new girder and $177 \mathrm{~mm}$ for the old girder. 350 grade steel plates were found to be the optimum grade as 250 grade was not adequate in design. The plate is attached to the girders using $20 \mathrm{~mm}$ diameter Ajax Oneside fasteners which are high strength 8.8/S structural bolts. The Ajax Oneside fasteners are a bolting system that enables the bolt to be tightened with only having access to one side of the bolt. Without the Ajax Oneside fasteners this retrofit would not be practical for some bridge girders. Figure 7 shows the arrangement of the Ajax Oneside fasteners in the order it is installed, which includes a bolt, collapsible washer, flat washer and a nut.

To perform the retrofit, the following equipment is required:

1. Bench drill press: To drill holes within the retrofitting plates off site within a controlled environment with no external factors affecting the process.

2. Magnetic drill press: For drilling the rivets in old girders for removal and to drill the holes within the bottom flange of the girders.

3. Hammer, cold chisel and pin punch: To remove the rivets within old girders to attach the retrofitting plate.

\section{Completed retrofit of girders}

Once all the drilling and rivet removal was complete the Ajax Oneside fasteners completed the retrofit by attaching the plate to the girders. Figure 8 shows the completed retrofit for the RMS 120-yearold girder. Figure 9 shows the completed retrofit for the EJF New equivalent girder.

\section{Results and Discussion}

\section{Introduction}

This investigation presents the results for the experimental study conducted. The results include the load versus deflection curve for the static fatigue test and the static strength test until failure conducted for

\begin{tabular}{|l|c|c|c|}
\hline Loading & $\begin{array}{c}\text { EJF New Equivalent } \\
\text { Girder Load (kN) }\end{array}$ & $\begin{array}{c}\text { RMS 120-year-old } \\
\text { Girder (kN) }\end{array}$ & $\begin{array}{c}\text { NO. of times loading } \\
\text { to be applied }\end{array}$ \\
\hline $40 \% \mathrm{P}_{\max }$ & 227.6 & 216 & 3 times \\
\hline \multicolumn{3}{|c|}{ Table 1: Static fatigue test summary. }
\end{tabular}

\begin{tabular}{|c|c|c|c|}
\hline Loading & $\begin{array}{c}\text { Retrofitted EJF New } \\
\text { Equivalent Girder } \\
\text { Load (kN) }\end{array}$ & $\begin{array}{c}\text { Retrofitted RMS } \\
\text { 120-year-old Girder } \\
\text { (kN) }\end{array}$ & $\begin{array}{c}\text { NO. of times } \\
\text { loading to be } \\
\text { applied }\end{array}$ \\
\hline $40 \% \mathrm{P}_{\max }$ & 227.6 & 216 & 3 times \\
\hline $60 \%$ of $\mathrm{P}_{\max }$ & 341.3 & 324.1 & 3 times \\
\hline $80 \% \mathrm{P}_{\max }$ & 455.1 & 432.1 & 3 times \\
\hline Until failure & $\geq 568.9$ & $\geq 540.1$ & Once \\
\hline
\end{tabular}

Table 2: Static strength test until failure summary.

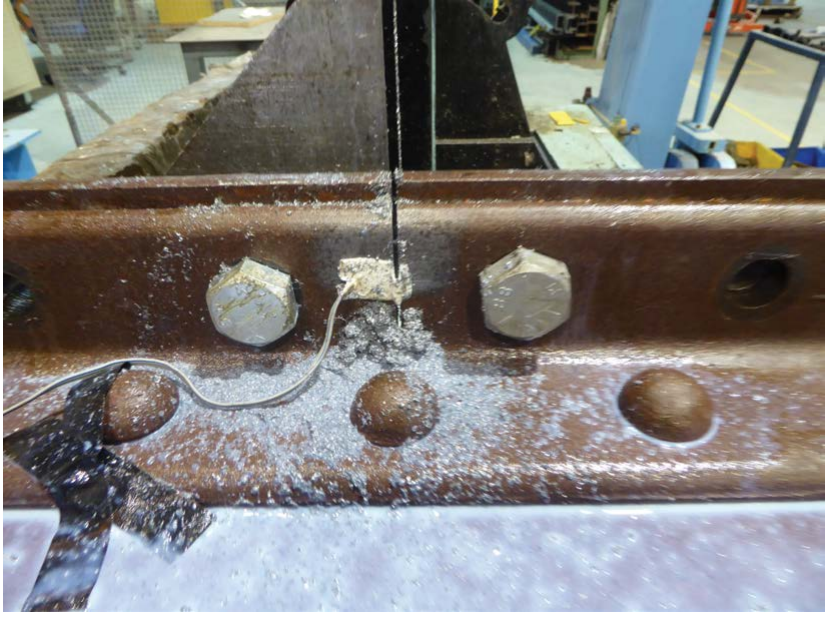

Figure 6: Artificially induced fatigue crack for 120-year-old girder.

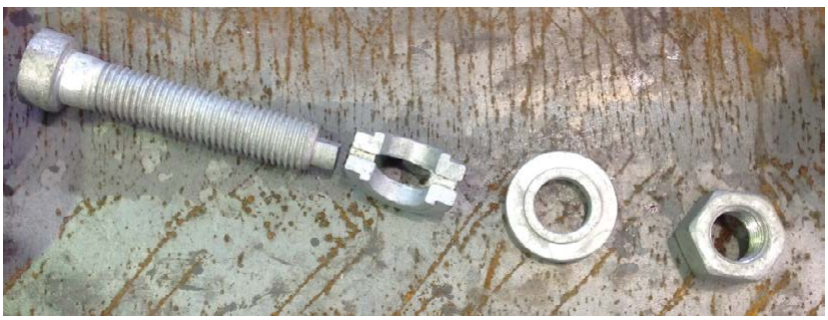

Figure 7: Ajax Oneside fastener.

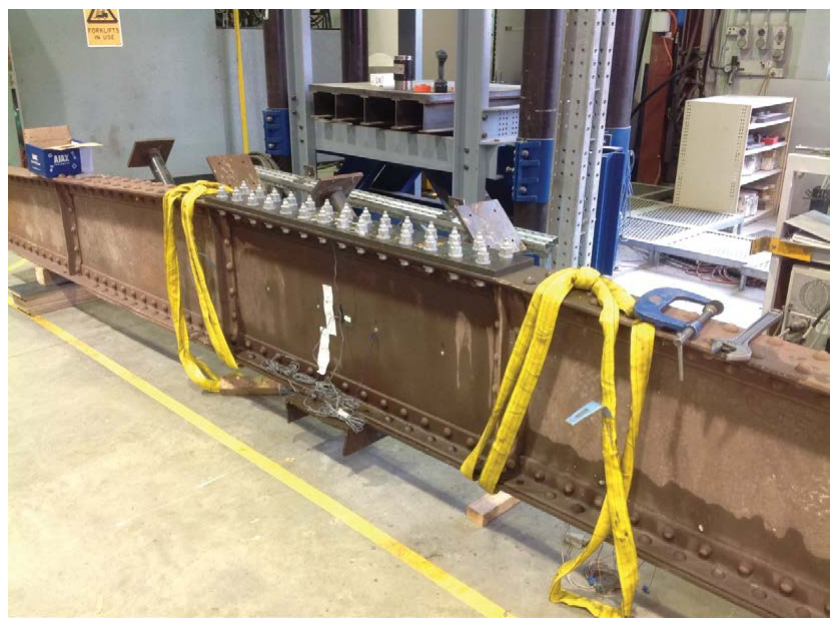

Figure 8: Completed retrofit for RMS 120-year-old girder.

the EJF new equivalent girder and the RMS 120-year-old girder. This investigation will also analyse the results and provide a comparison between the girders before and after the retrofit was conducted.

The experimental test was carried out within the testing laboratory at Western Sydney University, Kingswood campus. The girders were simply supported at each end as shown in Figure 5. The calculated theoretical ultimate applied point load for the EJF new equivalent girder is $568.9 \mathrm{kN}$ and for the RMS 120-year-old girder $540.1 \mathrm{kN}$. 
Citation: Mirza O, Milner L, Mashiri F (2018) Experimental Investigation of Retrofitting Techniques for Steel Bridge Girders Subject to Fatigue Failure. J Steel Struct Constr 4: 138. doi: 10.4172/2472-0437.1000138

\section{Experimental results}

New equivalent girder: The new equivalent girder had two experiments performed: before the girder had an artificially induced fatigue crack, and after the girder had an artificially induced fatigue crack that was retrofitted. Figure 10 shows a load versus deflection curve for the experimental results of the static fatigue test for the girder, and static strength test until failure for the retrofitted new equivalent girder. The load versus deflection curve was plotted due to the data obtained from the linear variable displacement transducers (LVDT), along with the known loading rate of $0.1 \mathrm{~mm} / \mathrm{s}$ for the $1000 \mathrm{kN}$ hydraulic press. Also displayed in Figure 10 is the experimental result from Dekruif [11], which is a static strength test until failure of an identical 610UB113 which is the same length and has vertical stiffeners in the same location; however, no retrofit was performed on the beam.

Figure 10 illustrates that the stiffness of the girder changed after the retrofit was installed on the girder. The girder initially had a stiffness of $26.14 \mathrm{kN} / \mathrm{mm}$. Once the girder had the artificial fatigue crack induced and the retrofitting plate installed, the stiffness decreased to $23.16 \mathrm{kN} / \mathrm{mm}$. The $11.4 \%$ decrease in stiffness is due to the artificially induced fatigue crack and the technique of the retrofit. Initially, the girder was a hot rolled uniform cross section with no discontinuities within the bottom flange. Once the artificial fatigue crack was induced in the bottom flange, it compromised the cross section of the girder reducing the stiffness. The connection of the retrofitting plate also affected the stiffness of the girder. The retrofitting plate was connected to the bottom flange using $20 \mathrm{~mm}$ diameter Ajax Oneside fasteners which were inserted to fill $22 \mathrm{~mm}$ holes within the flange and plate. The $22 \mathrm{~mm}$ holes were drilled so that the bolt had $2 \mathrm{~mm}$ of clearance. This caused the connection between the girder and the plate to slip as the Ajax Oneside fasteners would not engage with the plate and girder until the girder had deflected and engaged the fasteners with the outside of the holes for both the girder and retrofitting plate. Figure 11 shows the artificially induced fatigue crack propagating into the web of the new equivalent girder. This shows that the clearance of the bolt holes caused a slippage between the girder and retrofitting plate. This ultimately increased the deflection and reduced the stiffness of the girder. The slippage that occurred between the retrofitting plate and the girder is evident as the artificially induced fatigue crack was a $2 \mathrm{~mm}$ cut within the bottom flange. Once the testing was complete, the artificially induced fatigue crack had expanded to a $9 \mathrm{~mm}$ gap as seen in Figure 11. The result from the static strength test until failure for the retrofitted

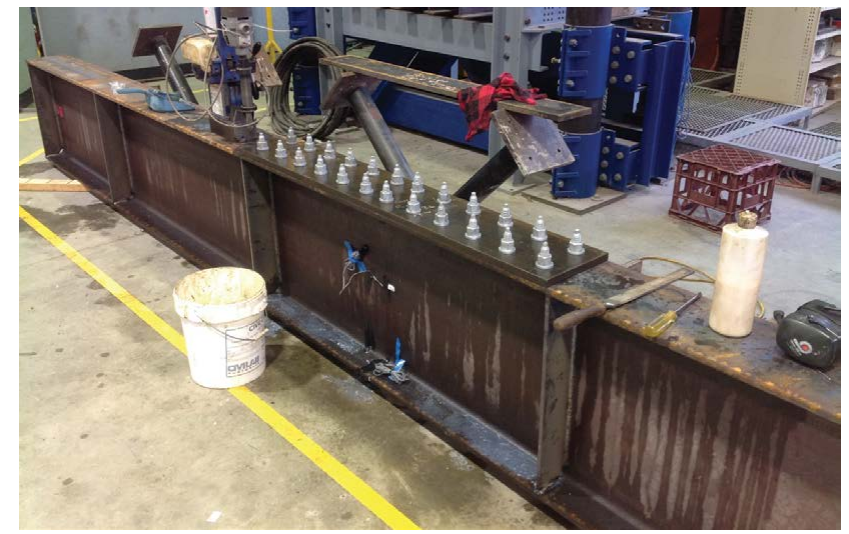

Figure 9: Completed retrofit for EJF new equivalent girder.

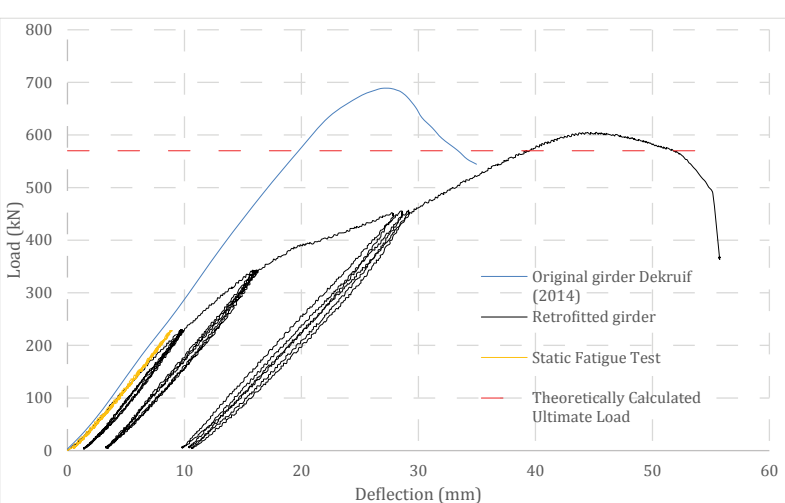

Figure 10: Load versus deflection curve for new equivalent girder experimental results.

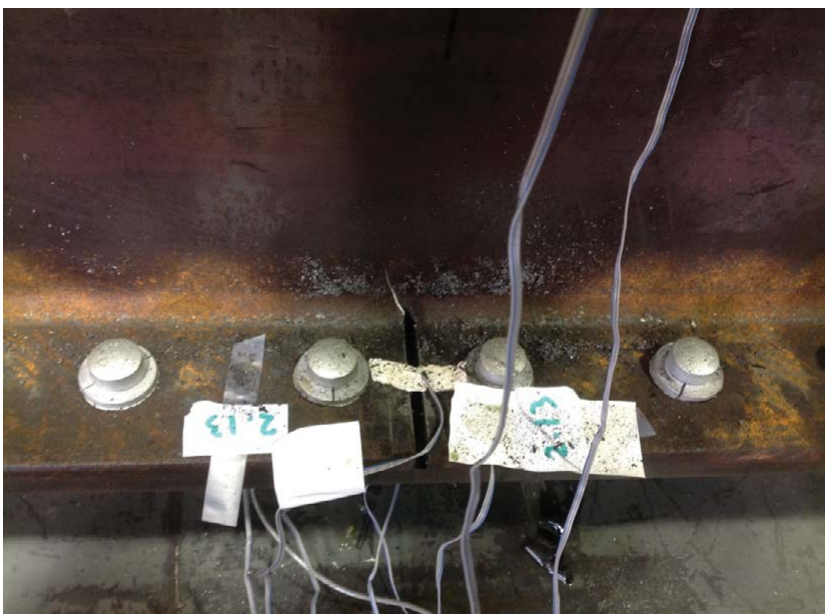

Figure 11: Artificially induced fatigue crack propagating into the web for new equivalent girder.

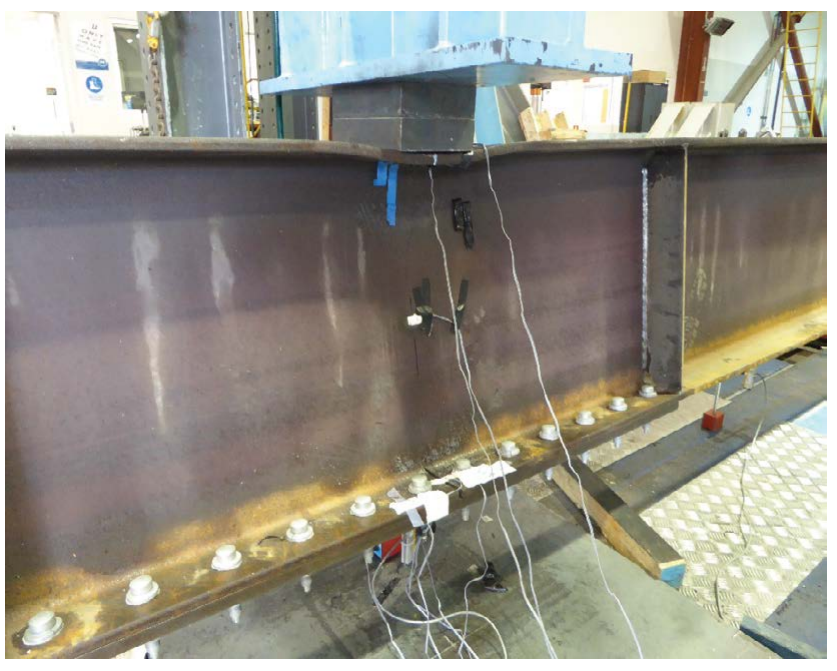

Figure 12: Local buckling within flange. 
new equivalent girder displayed in Figure 10 shows that retrofitting is effective for rehabilitating beams with fatigue failure within the bottom flange. It is seen in Figure 10 that the retrofitted new equivalent girder reached an ultimate applied point load of $604.86 \mathrm{kN}$. For a 610UB113 with a length of $6477 \mathrm{~mm}$, the theoretically calculated ultimate applied mid span point load was calculated as $568.9 \mathrm{kN}$. This corresponds to a $6.32 \%$ increase in the ultimate applied point load the girder can sustain before failure. This is not a significant improvement although it clearly validates that the retrofit can restore the girder to its original design loading capacity determined according to the Australian standards published by Standards Limited (2012) entitled Steel Structures [11]. Results for the original girder showed that the girder before the retrofit could sustain an ultimate applied load of $681.4 \mathrm{kN}$. Dekruif [11] showed the girder could sustain $76.54 \mathrm{kN}$ more than the retrofitted girder which corresponds to $12.65 \%$ decrease. However, as the results favour the original girder used [11], it can be seen in Figure 10 that the stiffness of the original girder used was greater than the girder used in this experimental study [11]. Original girder displays a higher stiffness and can resist a greater ultimate point load than the retrofitted girder. However, Figure 10 shows that the ductility of the retrofitted girder is greater than the original girder [11]. The greater ductility of the retrofitted girder is displayed, as the retrofitted girder yields and fails earlier than the original girder. Nevertheless, it is not as sudden and drastic as it sustains its ultimate point load for a longer duration.

The new equivalent girder showed several failure modes, such as experiencing distortional and local buckling. The top flange of the girder experienced local buckling due to a large compressive force applied to a small area across the top girder by the $1000 \mathrm{kN}$ hydraulic press, which is shown in Figure 12. Distortional buckling was evident within the flange and the web due to the lateral displacement caused through the application of the $1000 \mathrm{kN}$ hydraulic press. Figure 13 shows the distortional buckling within the flange and web. Due to the mode of failures, the designed retrofit for the new equivalent girder is validated as a justifiable technique for rehabilitating girders that have sustained fatigue failure within the bottom flange. As evident in Figure 12 , the plated retrofit did not sustain any form of failure and helped laterally restrain the girder. The retrofit was simple and cost effective whilst also repairing the girder to its design loading capacity proving it is the equivalent to a new girder that has not been in service. The retrofit

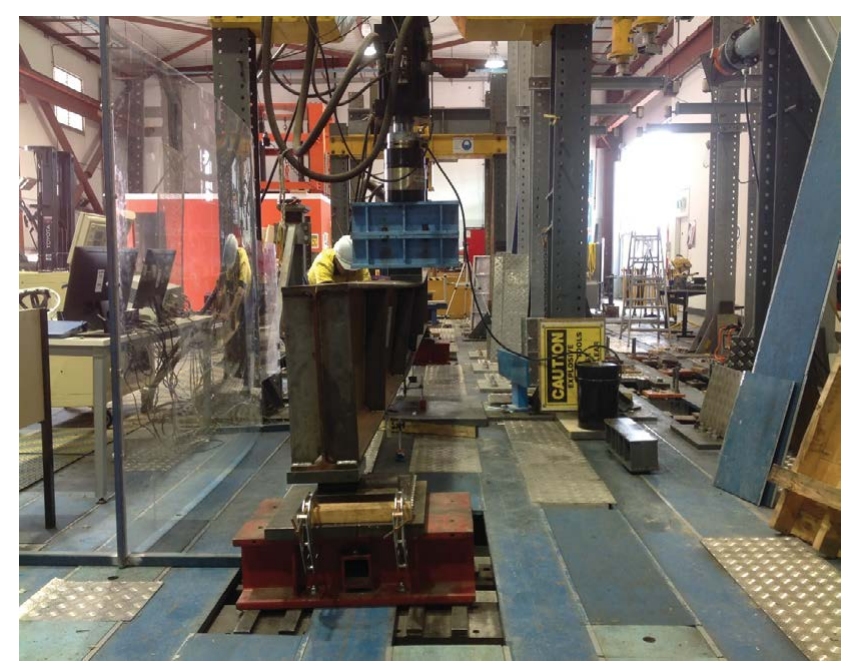

Figure 13: Distortional buckling in web. installed to the new equivalent girder is evidently a plausible technique for retrofitting steel bridge girders that have sustained fatigue failure within the bottom flange.

RMS 120-year-old girder: The RMS 120-year-old girder had two experiments performed: before the girder had an artificially induced fatigue crack, and after the girder had an artificially induced fatigue crack that was retrofitted. Figure 14 shows a load versus deflection curve for the experimental results of the static fatigue test for the girder and static strength test until failure for the retrofitted girder. The load versus deflection curve was plotted due to the data obtained from the linear variable displacement transducers (LVDT), along with the 1000 $\mathrm{kN}$ hydraulic press known loading rate of $0.1 \mathrm{~mm} / \mathrm{s}$. Also, displayed in Figure 14 is the experimental result from Dekruif's [11] experimental study which is a static strength test until failure of an identical 120-yearold girder that has experienced the exact same loading conditions and environment. The identical girder is the same length and has vertical stiffeners in the same location; however, no retrofit was performed on the beam.

From Figure 14 the stiffness can be calculated, showing that the girder used to conduct this experimental study and the original girder used in Dekruif s [11] study had the same stiffness of $27.82 \mathrm{kN} / \mathrm{mm}$. However, once the girder had the artificial fatigue crack induced and the plated retrofit installed, the stiffness decreased to $25.29 \mathrm{kN} / \mathrm{mm}$. The $9.1 \%$ decrease in stiffness due to the artificially induced fatigue crack and the connection of the plate to the bottom flange of the girder for the retrofit similar to the new equivalent girder. Figure 15 shows the artificially induced fatigue crack before the girder was tested. Figure 16 shows the artificially induced fatigue crack extending into the web and rivet hole after testing. This shows that the clearance of the bolt holes caused a slippage between the girder and retrofitting plate, ultimately increasing the deflection of the girder, which in turn reduced the stiffness of the girder. The slippage that occurred between the retrofitting plate and the girder is evident as the artificially induced fatigue crack was a $2 \mathrm{~mm}$ cut within the bottom flange. Once the testing was complete, the artificially induced fatigue crack had expanded to a 9 mm gap as seen in Figure 16.

The static strength test until failure results in Figure 14 for the retrofitted girder furthermore reinforces that retrofitting is an effective technique for strengthening and rehabilitating girders affected by fatigue cracks within the bottom flange. Figure 14 shows the RMS

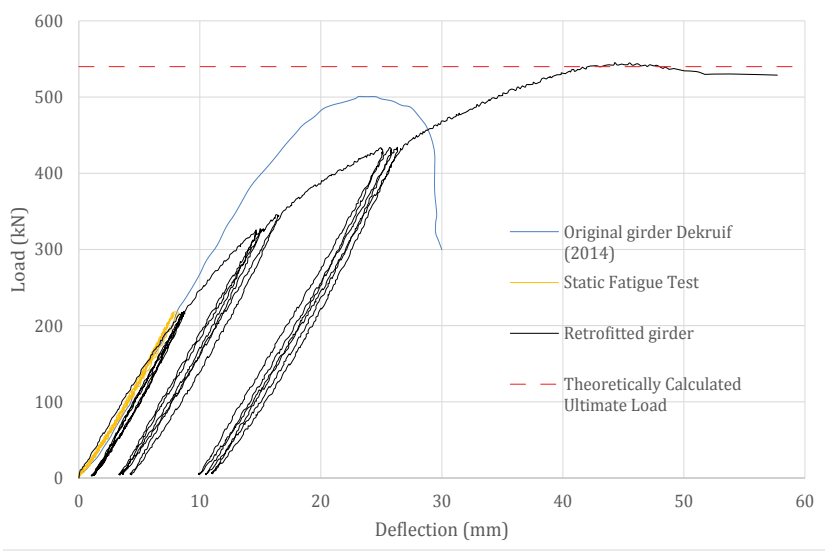

Figure 14: Load versus deflection curve for RMS 120-year-old girder experimental results. 
Citation: Mirza O, Milner L, Mashiri F (2018) Experimental Investigation of Retrofitting Techniques for Steel Bridge Girders Subject to Fatigue Failure. J Steel Struct Constr 4: 138. doi: 10.4172/2472-0437.1000138

retrofitted 120-year-old girder reached an ultimate applied point load of $544.84 \mathrm{kN}$. The maximum applied point load for the RMS 120 -yearold girder was calculated as $540.1 \mathrm{kN}$. The $0.88 \%$. Increase in the ultimate applied point load is negligible, however, it is noteworthy as the 120-year-old girder had experienced many years of loading over its service life and had accumulated damage that would negatively affect the ultimate applied point load the girder could sustain. Nonetheless, the retrofit performed upon the 120-year-old girder had rehabilitated the girder to its original design loading capacities, according to the Australian standards published by Standards Limited (2012) entitled Steel structures, which further validates the retrofitting technique. The ultimate applied point load was $8.73 \%$ higher than Dekruifs [11] experimental study results for the original 120 -year-old girder which had an ultimate applied point load of $501.1 \mathrm{kN}$. This further validates the retrofit and shows the need for retrofitting as Dekruif s [11] original 120-year-old girder did not reach its design load capacity. Another notable observation from the results in Figure 14 of the retrofitted 120 -year-old girder is the ductility. The ductility of the girder was significantly increased with the retrofit. The retrofitted girder maintains the ultimate applied load for a longer duration before failing, whilst the original girder reaches its ultimate load and drastically loses its strength and fails. This shows that the retrofitted girder has an improved ductility.

The failure mode of the retrofitted 120-year-old girder was due to distortional buckling within the flange and web of the girder similar to that of the new girder. Figure 17 shows the distortional buckling within the flange, whilst Figure 18 shows the distortional buckling within the web. The plated retrofit did not sustain any form of failure and helped laterally restrain the girder which is evident in Figures 17 and 18.

\section{Conclusion and Further Studies}

The objective of the research was to determine if it is feasible to rehabilitate girders that have experienced fatigue cracking within the bottom flange to their original condition. This has been achieved by designing and implementing a suitable retrofit. The results obtained from the experimental study are significant in validating the designed retrofit as a sustainable solution for steel bridge girders affected by fatigue within the bottom flange. Furthermore, the research supports the conclusive remarks in terms of providing a simple, effective, cost

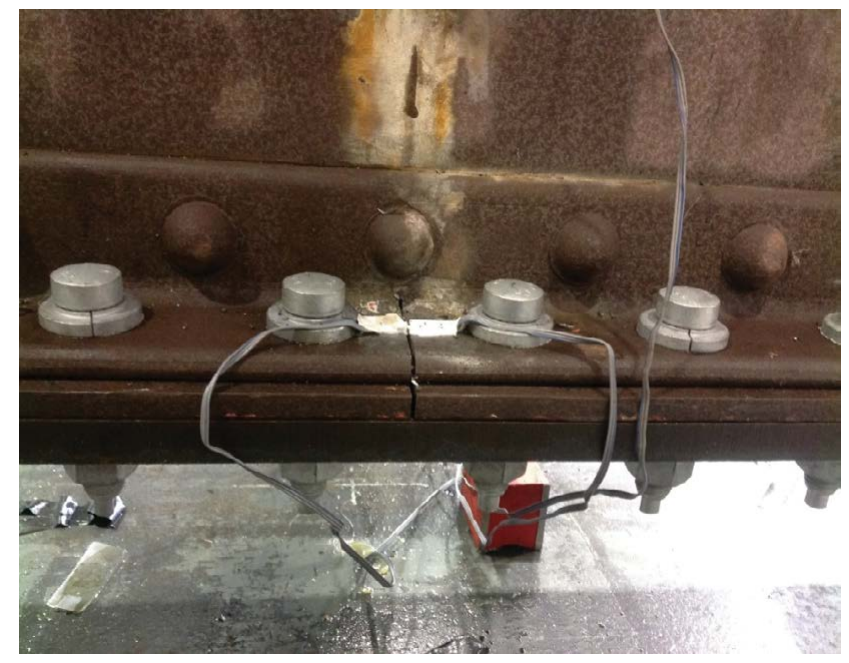

Figure 15: Artificially induced fatigue crack for RMS 120-year-old girder.

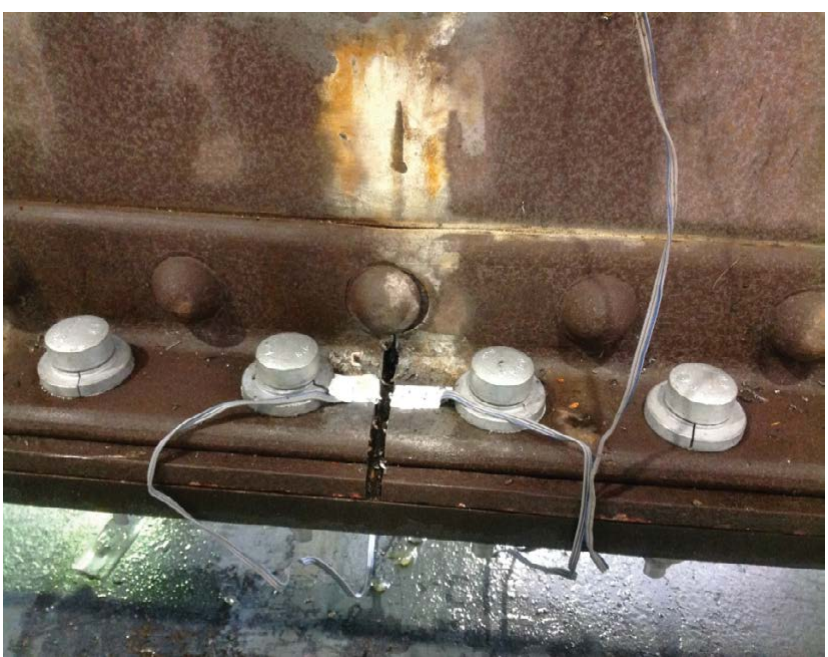

Figure 16: Artificially induced fatigue crack propagating into web of RMS 120-year-old-girder.

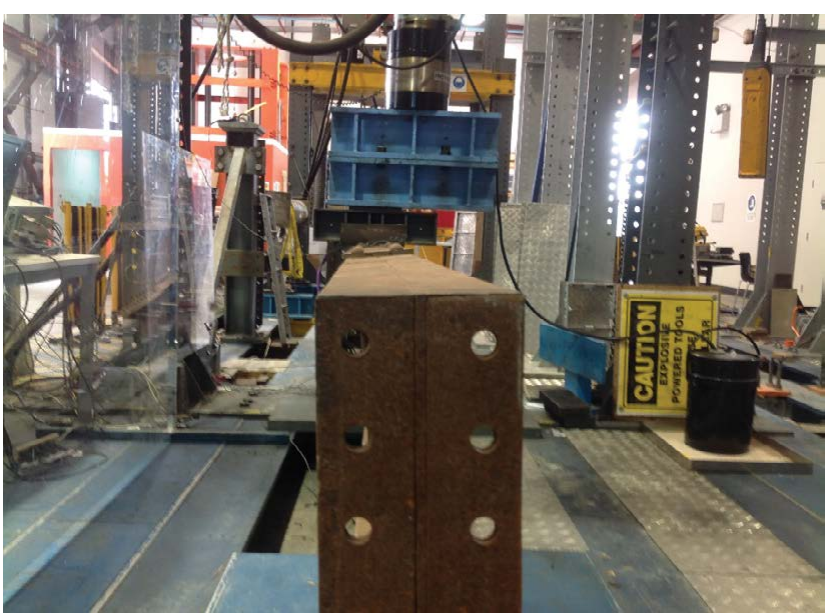

Figure 17: Distortional buckling within flange.

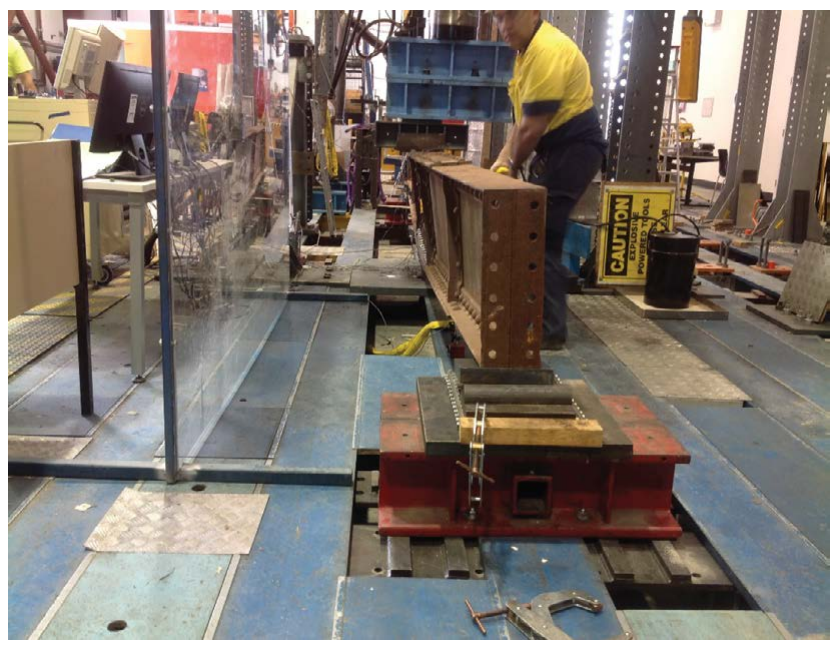

Figure 18: Distortional buckling within web. 
efficient and overall a sustainable means to retrofitting steel bridge girders due to fatigue failure.

The findings of the research herein are:

- The designed retrofit met all the necessary requirements for rehabilitating steel bridge girders as it is simple to install, cost efficient, sustainable and ultimately restored the two girders to their original design capacities. This is validated as the 120 -yearold girder and the new equivalent girder both surpassed their design ultimate load capacities determined by AS 4100 [12].

- The retrofitted 120-year-old girder and the retrofitted new equivalent girder experienced a slippage between the retrofitting plate and the girders. This negatively impacted the results, resulting in a reduced stiffness and ultimate applied. If the slippage can be removed it will improve the mechanical properties of the retrofitted girders [13].

- The retrofit was also designed to allow for the simplest installation process to minimise disruption of the steel bridge girders in service. The majority of the work required can be performed within a controlled environment where no external factors can influence the drilling of the retrofitting plate. The drilling of the steel bridge girders is performed with a magnetic drill press. Once all drilling is completed, the retrofit is installed with Ajax Oneside fasteners which are used to attach the retrofitting plate to the girder where access issues may be prominent.

- The retrofitting technique is not limited to steel bridges and can be implemented to any steel beam of any structure that has experienced fatigue failure in a flange.

- The results reinforce that existing structures do not necessarily need to be replaced; rather a simple designed retrofit is sufficient in restoring steel bridge girders to increase their service life providing a sustainable future. However, more research should be performed to guarantee the accuracy of the results before the implementation of the retrofitting technique to steel structures in service.

\section{Recommendations for Further Research}

Based upon the results obtained from the experimental study, further research can be performed to validate retrofitting as a simple technique for rehabilitating steel bridge girders. The recommendations for extending the research are based on the design aspect of the retrofitting technique to improve the results for the experimental study and finite element analysis. Listed below are the recommended areas that must be further researched to validate retrofitting as a solution for rehabilitating steel bridge girders due to fatigue failure?

1. Conduct a cyclic loading fatigue test upon the 120-yearold girder and the new equivalent girder. It would be ideal to conduct a cyclic loading fatigue test to determine where a fatigue crack would initiate from within the girder. Also, a cyclic loading fatigue test would generate an $\mathrm{S}-\mathrm{N}$ curve so the effects of the damage accumulated over the service life for the 120 -year-old girder can be compared with the new equivalent girder.

2. Reduce the effects of the slippage that occurred between the retrofitting plate and the girders to improve the retrofitting technique. One possible solution is to reduce the bolt clearance from $2 \mathrm{~mm}$ to $1 \mathrm{~mm}$. This will improve the stiffness of the girders in turn increasing the girders load capacity.

3. Consider finding the optimum design for the retrofit, either through a finite element analysis or redesigning the retrofit. This can be completed by finding the most efficient bolt spacing to reduce the number of bolts required. Finding the optimum thickness for the retrofitting plate, as the thickness of the plate can be reduced if a higher grade of steel is used.

\section{References}

1. Pipinato A, Pellegrino C, Modena C (2011) Fatigue assessment of highway steel bridges in presence of seismic loading. Engineering Structures 33: 202209.

2. Henderson I, Uy B, Zhu X, Mirza O (2014) The effect of retrofitted shear connection systems on the dynamic response of composite concrete stee beams. Twenty Third Australasian Conference on the Mechanics of Structures and Materials 2: 639-644.

3. Vázquez J, Navarro C, Domínguez J (2010) On the estimation of fatigue life in notches differentiating the phases of crack initiation and propagation. Fatigue \& Fracture of Engineering Materials \& Structures 33: 22-36.

4. Mirza O, Shill SK, Mashiri F, Shroot D (2017) Behaviour of retrofitted stee structures using cost effective retrofitting techniques. Journal of Constructional Steel Research 131: 38-50.

5. Maranian $P(2010)$ Reducing brittle and fatigue failures in steel structures American Society of Civil Engineers (1st edn.), Press, Reston, Virginia, USA.

6. Bandara C, Siriwardane S, Dissanayake U, Dissanayake R (2016) Full range $\mathrm{S}-\mathrm{N}$ curves for fatigue life evaluation of steels using hardness measurements. International Journal of Fatigue 82: 325-331.

7. Mashiri FR, Zhao XL, Grundy P (2004) Stress Concentration Factors and Fatigue Failure of Welded T-Connections in Circular Hollow Sections under In-Plane Bending. International Journal of Structural Stability and Dynamics, World Scientific 4: 403-422.

8. Mashiri FR, Zhao XL (2006) Thin Circular Hollow Section-to-Plate T-joints: Stress Concentration Factors and Fatigue Failure under In-Plane Bending Thin-Walled Structures 442, Elsevier Science Ltd pp: 159-169.

9. Dissanayake R, Bandara C (2016) Retrofitting of damaged bridges-the sustainable solution. International Journal of Urban Sciences 20: 50-59.

10. Schroot $D(2015)$ Retrofitted steel structures using innovative materials due to fatigue failure. Thesis, Penrith, Western Sydney University, Research Direct Database.

11. Dekruif B (2014) Fatigue behaviour of existing and new steel girders. Thesis, Penrith, Western Sydney University, Research Direct Database.

12. Standards Limited (2016) Steel Structures, AS 4100-1998. SAI Global Database.

13. Sahrapeyma A, Hosseini A, Marefat M (2013) Life-cycle prediction of stee bridges using reliability-based fatigue deterioration profile: Case study of neka bridge. International Journal of Steel Structures 13: 229-242. 